Volume 23

Issue 1 March

Article 13

March 1996

\title{
Technology Transfer and Integrated Social Development: International Issues and Possibilities for Social Work
}

James O. Billups,

Ohio State University

Maria C. Julia,

Ohio State University

Follow this and additional works at: https://scholarworks.wmich.edu/jssw

Part of the International Economics Commons, and the Social Work Commons

\section{Recommended Citation}

Billups,, James O. and Julia,, Maria C. (1996) "Technology Transfer and Integrated Social Development: International Issues and Possibilities for Social Work," The Journal of Sociology \& Social Welfare: Vol. 23 : Iss. 1 , Article 13.

Available at: https://scholarworks.wmich.edu/jssw/vol23/iss1/13 


\title{
Technology Transfer and Integrated Social Development: International Issues and Possibilities for Social Work
}

\author{
JAMES O. BILLUPS \\ The Ohio State University \\ The Inter-University Consortium for \\ International Social Development \\ MARÍA C. JULIÁ \\ The Ohio State University \\ College of Social Work
}

\begin{abstract}
Technology transfer and integrated social development are closely linked aspects of social work practice that deserve more serious attention than they have received to date. Social workers need to play more knowledgeable and active roles in utilizing a broad-scale partnership model that will help communities and societies screen and adapt technologies so that they can be appropriately integrated with people's values, culture, concerns and aspirations. Everyone should ultimately benefit if the poor and disempowered peoples of the world in particular become the primary focus and the beneficiaries of less arrogant and more inclusive strategies of technology transfer. The aim of the paper is to examine models for screening and transferring technology and reviewing practice principles and prospects for achieving a concerted social work approach to technology transfer and integrated social development.
\end{abstract}

The extent to which technology for human welfare can be successfully transferred and applied across cultures has been repeatedly and vehemently questioned by scientists from a variety of disciplines (Conyers, 1982; Bonair et al., 1989; Madu, 1992; among others). In fact, analysts have documented that the transfer of technology too often has served as a means to exploit communities or countries and make them culturally, economically or politically dependent, often for the benefit of a relatively few of the political and economic elite in donor countries and receiving countries 
(Jarrett, 1989; Hellinger et al, 1988). Therefore, although international technology transfer can play a decisive part in the process of furthering the social development of the broad masses of people, experience has shown that much transfer of technology in the latter part of this century "has not helped in the relief from poverty and hunger in the Third World ... most of which remains ill-fed, ill-clad, ill-housed and illiterate" (Patel, 1978, p. 304-305). As one analyst has indicated, the consequences of technology causing concern at the present-pollution and damage to the environment, occupational and social dislocations, threats to significance of the individual-are in large measure because nobody has foreseen them. "They have fallen between innumerable individual decisions to develop individual technologies without explicit attention to what all these decisions add up to for society as a whole and for people as human beings" (Mesthene, 1993, pp. 79-80).

Several authors have written on ways for social workers to participate in improving cross-cultural technology transfer. (See, for example, Khinduka, 1971; Sanders, 1977; Midgley, 1981; Healy, 1986; Abrahams and Chandrasekere, 1990; and Kondrat, 1994). The focus of these endeavors has been centered primarily on the transfer of social work intervention models and social work programs of education (processes Meinert and Faherty, 1981, and Chatterjee and Ireys, 1979, have referred to as "social technology transfer", and Abrahams and Chandrasekere, 1990, have termed "educational technology transfer"). Yet, on the whole, close attention to the role of social work in dealing broadly with the effects of international and cross-cultural technology transfer on the lives of the masses, and particularly of the poor, has been rather conspicuous by its absence.

The highly complex and troubled world of today forces a compelling new challenge for social workers to contribute much more consciously and actively than heretofore to the field of technology transfer. In addition to technology-promoted problems of a social nature already cited, substantial worldwide poverty, accelerated population growth of aged persons, increases in rates of refugee flight, and spread of inter-ethnic and international conflicts are but a few of the additional social problems that are likely to alter profoundly the patterns of human service delivery in coming years (Estes, 1992). Few existing social welfare systems are proving adequate, and consequently, governments and others 
are seeking new, better organized human service technology to address such problems throughout the world.

Given the challenges just outlined, the aim of this paper is to examine models for screening, transferring and using appropriate technology for achieving improved human service delivery and for realizing long term, concerted and integrated processes of socio-economic development. Such efforts at service delivery and socio-economic development, as the literature recognizes, need to be reasonably sustainable, broadly based and people-oriented. Technology so viewed as a philosophy or set of design criteria that is increasingly transferred across cultural and national boundaries has sometimes been referred to not only as appropriate or alternative technology, but also as "self-help technology, or democratic or people's technology-a technology to which everyone can gain admittance and which is not reserved to those rich and powerful" (Schumacher, 1973, p. 54).

\section{Integrated Social Development}

Ideally, the integrated social development to which the above technology can contribute is geared to developing the long-term capacity of communities and societies to function for the wellbeing of all of their members. According to Heller (1986), an inclusive, integrated development is a means by "which people and their communities change to improve their lives [through] ... economic, social, [and] at times technological, and political (i.e., decision making) processes" (p. 3).

As opposed to relief efforts which focus on current crises, integrated socio-economic development efforts are aimed at correcting the underlying causes of problems and, in the process of doing so, they seek to empower people (Rosenthal, 1990, p. 225). Such efforts include "not only specific technical objectives but also ... regard for the social well-being of citizens through their own participation. Integrated development efforts are well rooted in and congruent with the culture and traditions of communities" (Martínez-Brawley \& Delevan, 1993, p. 178).

Technology and its Transfer: Pros and Cons

Technology of various kinds, but particularly the aforementioned alternative people's technology, is integral to sound social 
development of organizations, communities and societies. Such technology arises from the demand for solutions to problems associated with human needs and when put to use in peopleoriented ways refers to knowledge, procedures, and materials aimed at improving quality of life (Svob-Dokic, 1986, p. 180). Technology in the human services and social professions is broadly considered to consist of "the procedures, methodologies and processes-the inventions-through which an organization [or community or society] accomplishes its goals" (Brager and Holloway, 1978, p. 47). Such technology with a human face tends, perhaps most often in the less industrialized societies but on occasions in industrialized societies as well, to "stress simplicity, individual worth and self-reliance, labor-intensiveness rather than capital intensiveness, minimum energy use, consistency with environmental quality, and decentralization rather than centralization" (Teich, 1993, p. 229).

Wide-ranging perceptions vary from technology serving at one extreme as a panacea for all ills (Roche, 1983, p. 343) to the other extreme of reducing the capacity of people to care for themselves (Illich, 1976). Some authors argue that problems with technology often arise either from the nature of technology itself (Long, 1979, p. 273) or from the insufficiency of support systems to enable people to receive, use and benefit from those technologies (CSDHA, 1989, p. 278). For other observers the negative impacts of technology are not necessarily inherent in the technology or in the recipients' supportive systems, but lie, instead, in the imperfect transfer processes.

Technology transfer, according to Derakhshani and Van Gigch (cited in Madu, 1992), refers to the acquisition, development, and utilization of new knowledge and related "inventive activity" within an organization, community or country other than that in which the knowledge and activity originated (p. 2). Such transfer often implies either expensive outlays, an established reservoir of expertise or an importation of expertise, any of which simply may be unaffordable or unrealistic for many of the poorer communities or countries of the world (Armijo, 1989, p. 51). Transfers of alien interventions detached from indigenous realities typically have been "supply oriented programs" (McCormack, 1989, p. 683) controlled largely by transnational corporations, universities, 
governments and other groups of the industrially developed countries that frequently have been far removed from the reality of the receiving country's hunger, poverty, illiteracy, social injustice, and diseases (Roche, 1983, p. 349). Based on the mistaken assumption that "Western technology is ipso facto appropriate" for the advancement of developing countries (Reddy, 1977, p. 152), many efforts at development planning and programming in developing countries have been focused to date first and foremost on what could be done for the good of the elite few. Classic examples have been the transfer of technologies for the establishment of expensive "high tech" medical facilities provided largely for the wealthy populations of poor countries when the institutionalization of simpler and much less costly but basic prevention-e.g., universal childhood immunizations or oral rehydration programs-would have been much more beneficial to the population as a whole.

\section{Technology Transfer and Social Work}

Much international, cross-cultural transfer of social work practice methodology has been a reflection of those widespread technology transfers that have had scant relevance to the needs of the poor. In social work the transferred technology flowing from the global North to the global South, has been judged frequently to have assumed something of the character of professional imperialism. That is, "inappropriate ideas, institutions and technologies have been replicated in the Third World" (Midgley, 1981, p. xiii). In the Westernized countries, social work is commonly understood to mean working with people one-to-one. "Critics see this ... as unrealistic because the human problems this approach seeks to tackle often are social in nature, arising out of relationships" and conditions and consequences which extend well beyond the individual (Jones, 1990, p. 189). In countries of the South, people customarily share problems and arrive at solutions within the context of a family or other village or community group rather than in the one-to-one privacy characterized by an individual interview.

In much this same vein, Kondrat (1994) points to a South Asia experience of inappropriately transplanted social work 
technology. She has noted, how social work education models emphasizing knowledge of social action, social development and structural change would serve the cultural values and needs of India more appropriately than the transferred educational models that have overemphasized alleviation of personal distress and individual adjustments.

While technology transfer in general and social technology transfer in particular can represent a valuable humanitarian action, mishandled transfers and the cultural invasion by the transported technology can lead to cultural dependency, erosion and retardation. Lay citizens and professionals in the technology-receiving social units may be diverted from designing and implementing their own strategies of self-reliance, self-sustenance, confidence and competence (Sikkink, 1989) by "modern conquistadors" (Ovitt, 1989). "The invasion of underdeveloped countries by new instruments ... organized for financial efficiency rather than local effectiveness and for professional rather than lay control inevitably disqualifies tradition and autonomous learning ..." (Illich, 1976, p. 218).

Our contention is that all professionally educated social workers should be made aware of these kinds of dangers. Moreover, members of the profession and of related fields need to possess the fundamental competence to contribute knowledgeably to people in organizations, communities and societies in their efforts at developing, receiving or adapting technology that is appropriate for indigenous, local cultures and for integrated social development. A problem noted by Cetingok and Hirayama (1990) and Lyons (1983), however, is that by and large students in current-day social work educational programs tend to be exposed to a microcosmic view of the world that seriously limits their ability to understand such macro issues. Put another way, in the USA and in many other parts of the world, social work remains more concerned "with the biography of the person than the drama of society" (Khinduka, quoted in Midgley, 1981, p. 148). This may be due, at least in part, to the prevailing professional perception that "intrapsychic technologies have been relatively well developed... while the technologies directed toward influencing environmental arrangements remain relatively undeveloped and untaught" (Frumkin and $\mathrm{O}^{\prime}$ Connor, 1985, p. 15). For whatever the reason, 
social workers entering the profession customarily do not hold a sufficiently broad understanding of technology transfer and how it can both influence and be influenced.

What then appears to be at the heart of the problem and a possible solution? Patel (1987) points to two limitations to social workers taking on an inclusive social work practice commitment and approach in helping people to influence more appropriate technology development and transfer decisions. She asserts that the major social work limitations are 1) a lack of sufficient professional education and 2) the consequent practitioner resistances and fears about change (p. 233). Since resistances and fear can often be overcome with the help of strengthened knowledge and resulting competence and confidence, the educational shortcomings Patel identifies may be most directly and readily addressed with the help of the introduction of new and strengthened curricula emphases and content in schools of social work.

\section{Screening Technology}

Our examination of the above issue indicates three broad areas of new knowledge and competence needed by social workers -skills in identifying appropriate technology; in aiding development and adoption of appropriate technology by and from within a community or society; and in facilitating the transfer, adaptation and integration of such technology from outside a community or society. For example, before helping people in communities or wider social units to implement change efforts aimed at improving human well-being, Piachaud (1979, pp. 640-641) maintains that the technology-related kinds of questions social work professionals skillfully need to help people answer are ones such as these. 1) How many people will the technology serve and what will be the benefit? 2) How many people could be served, and to what benefit, through alternative uses of resources? 3) What would be the likely costs, i.e., not only in capital outlays, but in availability of the skilled person-power to apply the technology and to keep it going?

Reddy (1977) has set forth other useful criteria for screening technology for people-sensitive appropriateness. They include consideration of 1) ability to make use of local skills; 2) conduciveness to indigenous participation and self-reliance; 3 ) low 
cost; 4) ability to be incorporated into the fabric of social life and blended with traditional technologies; and 5) ability to lead to an enhancement of the quality of life rather than an increase in consumption of technology (pp. 160-163).

Naess (1989) raises still other questions to test whether or not a supposed technical advancement will benefit a society and its people. Among his questions are these: "Is it conducive or dangerous to health? How meaningful . . . to the self-determination and inventiveness of the worker? Does it strengthen harmonious togetherness with other workers? . . . Does it promote equality or class differences? How vulnerable [is it] in times of crisis? (p. 95).

Finally, Madu (1992) adds that among other requirements, technologies must be compatible with the prevailing ethical and value system of groups to be effected. Technologies must be introduced gradually (given that the innovations are based on knowledge and skills that may need to be slowly developed), and they must be invested in training and education (this latter requirement is also considered the most important criterion by Roche, 1983, p. 354).

\section{Models and Prospects}

At minimum, the process of analyzing appropriateness of technology, and its development and transfer, requires an ability to make sensitive use of an analytic three-level framework (Bonair et al., 1989). The three levels are 1) an understanding of the dynamic interplay of individual carriers and receivers of technology, 2) the structure of the receiving social system, and 3) the technology itself (pp. 772-773). A thorough-going mindhold on the social work simultaneous dual commitment and focus on people and environment and their transactions fits well with such a paradigm. It calls for polyvalent change agents to embrace an ecological orientation, to operate within an interdisciplinary context, to facilitate people empowerment rather than dependency, to respect cultural differences, and to utilize indigenous resources and practices. Thus, social work principles that sensitively stress collective participation of people in the defining of their own needs and goals, planning and choosing alternative courses of action, implementing such plans and actions, and evaluating the 
outcomes must be essential to the entire process if careful and effective creation, transfer, adaptation and integration of appropriate technology is to take place and to "stick."

The social worker's aim in use of such an integrated ecosystemic-oriented model is to collaborate with people to "make sense and find meaning" within their circumstances (Goldstein, $1986, p .153)$. In this vein, the advantage, if not the outright necessity, of incorporating indigenous knowledge of local people with that of the "experts" in planning, implementing and evaluating development projects and technology transfer has been illustrated dramatically in a number of experiences. In addition to the earlier brief mention of medical and social work examples, one taken from a rural development project further exemplifies this theme. A new irrigation project in Nepal, described as a marvel of engineering design, provides lift pumps and piped water to supply precise water control to farmers. However, the farmers, without voice in the design decisions, preferred a gravity flow system with technologies they knew and could manage. Instead, they now must cope with interrupted water supply whenever hydroelectric power is diverted to Kathmandu. Moreover, the system of piping does not allow the cold river water to warm in the sun, as happened with their traditional gravity-channel system. Crops do not do as well because of the differences in water temperature. Farm operations suffer. (Uphoff, 1991, p. 475). Clearly, this technology transfer would have been modified or even refused outright by the people had a participatory partnership model been implemented and the goal of farmland irrigation had been viewed as more than a problem to be solved by the "outside" elite, bankers, government officials and engineers alone.

Unfortunately, in some communities and countries on the world scene, a more inclusive participatory approach of integrated development as the vehicle for transfer, adoption and/or modification of technology is unlikely to gain acceptance or to be effective due to the local political climate or the established, culturally determined ways of doing things. Nonetheless, several promising trends should give advocates of a broadly based social development-oriented social work considerable encouragement. Uphoff (1991) notes that some changes have been occurring in various parts of the world that now seem to favor programs aimed 
at "bringing in the poor," not just as beneficiaries, but as real partners. These changes are:

The expectation that strictly technocratic, nonparticipatory approaches can 'deliver the goods' has lost credibility in recent years .... Political elites ... and some leading actors ... [now] champion bottom-up approaches ... . because of favorable ideological orientations, fear of ... disorder, or apprehension over what an increasingly unjust future otherwise holds for the next generation.

Governments are facing overwhelming fiscal problems .... There is more need than before to put all available resources to their best possible uses... [and this] requires greater local participation.

[Moreover, in some parts of the world] . . capabilities of the poor majority have been upgraded over the last thirty years by education, health, communication and other investments. . . Selfmanagement of development tasks is now more feasible (p. 503).

\section{Conclusion}

Making new social and educational technology available in culturally sensitive ways with respect to marginalized, poor and deprived peoples is an area of publicly avowed concern of a growing number of social work professionals world-wide. However, this concern has not been translated sufficiently into professional social work education or practice. Much more concerted efforts are needed to develop and adopt a professional partnership model of social work. Such efforts are necessary to help counteract any tendency to contribute to the widespread technological arrogance that has been defined as "a support for technologies, often of limited social utility or questionable technical feasibility, whose introduction leads to an underestimation of environmental or social costs" (Josephson, 1992, p. 26).

Certainly, new and more appropriate technology developed from within a community or society, as well as technology transfers from outside, continue to be necessary for any community or nation that desires to help large numbers of its people break out of the cycle of poverty. However, while technology can be used to the benefit of humankind, concern must also be focused on how it is often used to the detriment of people. Inappropriate technology creation and transfer is described as a sometimes subtle and sometimes blatant form of institutionalized violence that results from a small elite group of privileged people benefiting 
in great excess at the expense of the majority of the population who in many societies are the poor. It is one of many types of violence that needs to be recognized and countered by the social work profession everywhere if, as Van Soest and others (1987) have observed, "The task of social work is to reaffirm its alliance with the oppressed and extend its commitment to the principles of respect and non-violence into areas where up to now it has not been generally acknowledged" (p. 83).

A major challenge is for social workers to join actively with other socially concerned and culturally sensitive professionals, social scientists, citizen leaders and government officials in providing new forms of local, national and international technology development, transfer, adoption or adaptation to support the well-being and human realization of all people. Until now, however, except for a relatively few, social workers like others in the social sciences and social professions "have been busier advocating [such] participation than working out social techniques for organizing it" (Cernea, 1991, p. 25).

To be effective, polyvalent agents of integrated social development must become proficient in the organizing and implementing skills that facilitate broad-scale participation of all social interests and groups, and particularly those people who are the poorest and most disempowered, in defining the types of technologies most affecting their lives. To do this is likely to require increasingly careful educational preparation and deployment of many more social workers with a combinative knowledge base and a practice repertoire that draws from generalist, feminist, eco-systemic and social development orientations (Billups and Juliá, 1991). Such a practice frame of reference and approach can serve a crosscommitment of goals that reflect concerns and aspirations for and of all people. Moreover, such an inclusivity model will help social workers to act on their belief that communities and societies are measured ultimately by the way they treat their members, particularly those who are their least privileged.

\section{References}

Abrahams, C., \& Chandrasekere, S. (1990). Transferring educational technology through a social development model of consultation. International Social Work, 33(3), 213-223. 
Armijo, L. (1989). The application of expert systems to problems in development. Social Development Issues, 12(2), 51-59.

Billups, J., \& Juliá, M. (1991, October). The fourth world in the USA: Need for convergent generalist, feminist and social development approaches. International Social Work, 34(4), 325-337.

Bonair, A., Rosenfield, P., \& Tengvald, K. (1989). Medical technologies in developing countries: Issues of technology development, transfer, diffusion and use. Social Science and Medicine, 28(8), 769-781.

Brager, G., \& Holloway, S. (1978). Changing human service organizations: Policies and practice. New York: Free Press.

Centre for Social Development and Humanitarian Affairs (CSDHA). (1989). World survey on the role of women in development. New York: United Nations.

Cernea, M. M. (1991). Knowledge from social science for development policies and projects. In M. M. Cernea (Ed.), Putting people first: Sociological variables in rural development (pp. 1-41). New York: Oxford University Press.

Cetingok, M., \& Hirayama, H. (1990). Foreign students in social work schools: Their characteristics, and assessment of programmes in the US. International Social Work, 33(3), 243-253.

Chatterjee, P., \& Ireys, H. (1979). Technology transfer: Views from some social science disciplines. Social Development Issues, 3(3), 54-76.

Conyers, D. (1982). An introduction to social planning in the Third World. New York: J. Wiley.

Estes, R. J. (Ed.). (1992). Internationalizing social work education: A guide to resources for a new century. Philadelphia: University of Pennsylvania School of Social Work.

Frumkin, M., \& O'Connor, G. (1985, Winter). Where has the profession gone? Where is it going? Social Work's search for identity. The Urban and Social Change Review, 18(1), 13-18.

Goldstein, H. (1986). Education for social work practice: A cognitive, crosscultural approach. International Social Work, 29(2), 149-164.

Healy, L. (1986). The international dimension in social work education: Current efforts, future challenges. International Social Work, 29(2), 135-147.

Heller, P. (1986). Profiles in development: Basic needs and developing nations. Social Development Issues, 10(2), 3-17.

Hellinger, S., Hellinger, D., \& O'Regan, F. M. (1988). Aid for just development. Boulder: Lynne Reiner Publishers.

Illich, I. (1976). Medical nemesis: The expropriation of health. New York: Pantheon Books.

Jarrett, A. (1989). Implications of transferring social technology to developing nations and corrective strategies. Journal of International Comparative Social Welfare, 5(1), 33-44.

Jones, H. (1990). Social welfare in third world development. London: MacMillan.

Josephson, P. R. (1992). Science and technology as panacea in Gorbachev's Russia. In J. P. Scanlan (Ed.), Technology, culture and development: The experience of the Soviet model (pp. 25-61). Armonk, NY: M. E. Sharpe, Inc. 
Khinduka, S. (1971). Social work and the Third World. Social Service Review, 45(1), 62-73.

Kondrat, M. E. (1994). Culture and power in technology transfer: Perspectives from a critical Sociology of knowledge. Social Development Issues, 16(3), 4567.

Long, F. (1979). The role of social scientific inquiry in technology transfer. American Journal of Economics and Sociology, 328(3), 261-274.

Lyons, P. (1983). Ideology in social welfare policy instruction: An examination of required readings. Journal of Sociology and Social Welfare, 10(3), 376-389.

Madu, C. (1992). Strategic planning in technology transfer to less developed countries. N.Y.: Quorum Books.

Martínez-Brawley, E., \& Delevan, S. M. (1993). Transferring technology in the personal social services. Washington, DC: National Association of Social Workers.

McCormack, C. (1989). Technology and women's health in developing countries. International Journal of Health Seroices, 19(4), 681-692.

Meinert, R., \& Faherty, V. (1981). Appropriate technology transfer for public social services. Journal of Continuing Social Work Education, 1(2), 15-19, 27.

Mesthene, E. G. (1993). The role of technology in society. In A. H. Teich (Ed.). Technology and the future (pp. 73-88). New York: St. Martin's Press.

Midgley, J. (1981). Professional imperialism: Social work in the Third World. London: Heinemann.

Naess, A. (1989). Ecology, community and lifestyle. London: Cambridge University Press.

Ovitt, G. (1989). Appropriate technology: Development and social change. Monthly Review, 40, 22-32.

Patel, S. (1978). Comment. Impact, 28(4), 303-311.

Piachaud, D. (1979). The diffusion of medical techniques to less developed countries. International Journal of Health Services, 9(4), 629-641.

Reddy, A. (1977). The transfer, transformation, and generation of technology for development. Labour and Society, 2(2), 145-171.

Roche, M. (1983). Science transfer and technology transfer: Comments on two Venezuelan cases. Science of Science, 4(12), 3, 343-355.

Rosenthal, B. (1990). U.S. social workers' interest in working in the developing world. International Social Work, 33(3), 225-232.

Sanders, D. (1977). Developing a graduate social work curriculum with an international-crosscultural perspective. Journal of Education for Social Work, 13(3), 76-83.

Schumacher, E. F. (1973). Small is beautiful-Economics as if people mattered. New York: Harper Torchbooks.

Sikkink, K. (1989). Codes of conduct for transnational corporations: The case of the WHO/UNICEF code. In F. Paul (Ed.). The Politics of International Organizations (pp. 342-363). Chicago: Dorsey Press.

Svob-Dokic, N. (1986). The cultural dimension of technological development of developing countries. Development International, 1(1), 179-188. 
Teich, A. H. (1993). Reshaping technology. In A. H. Teich (Ed.), Technology and the future (pp. 229-230). New York: St. Martin's Press.

Uphoff, N. (1991). Fitting projects to people. In M. M. Cernea (Ed.), Putting people first: Sociological variables in rural development (pp. 467-511). New York: Oxford University Press.

Van Soest, D., Johnston, N., \& Sullivan, M. (1987). Orientation to peace and justice in professional social work education in the United States. Social Development Issues, 10(3), 81-99. 